\title{
Optimizing Child Nutrition Education With the Foodbot Factory Mobile Health App: Formative Evaluation and Analysis
}

Jacqueline Marie Brown ${ }^{1}$, MHSc; Robert Savaglio², BIT; Graham Watson ${ }^{2}$, BIT; Allison Kaplansky ${ }^{3}$, MSc; Ann LeSage $^{4}, \mathrm{PhD}$; Janette Hughes ${ }^{4}, \mathrm{PhD}$; Bill Kapralos ${ }^{2}, \mathrm{PhD}$; JoAnne Arcand ${ }^{1}$, PhD, RD

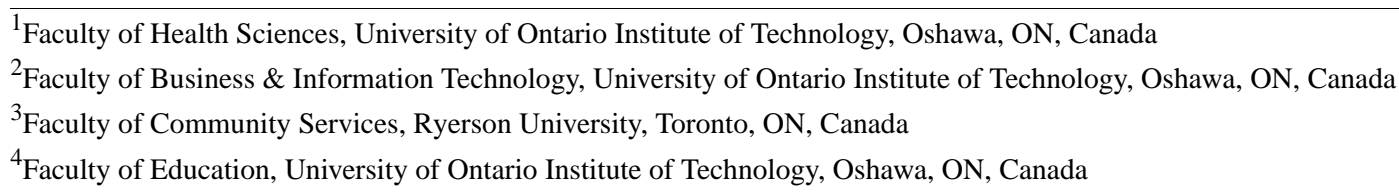

Corresponding Author:

JoAnne Arcand, PhD, RD

Faculty of Health Sciences

University of Ontario Institute of Technology

2000 Simcoe Street North

Science Building Rm 3016

Oshawa, ON, L1G 0C5

Canada

Phone: 1 (905) 7218668 ext 3796

Fax: 1 (905) 7213179

Email: joanne.arcand@uoit.ca

\section{Abstract}

Background: Early nutrition interventions to improve food knowledge and skills are critical in enhancing the diet quality of children and reducing the lifelong risk of chronic disease. Despite the rise of mobile health (mHealth) apps and their known effectiveness for improving health behaviors, few evidence-based apps exist to help engage children in learning about nutrition and healthy eating.

Objective: This study aimed to describe the iterative development and user testing of Foodbot Factory, a novel nutrition education gamified app for children to use at home or in the classroom and to present data from user testing experiments conducted to evaluate the app.

Methods: An interdisciplinary team of experts in nutrition, education (pedagogy), and game design led to the creation of Foodbot Factory. First, a literature review and an environmental scan of the app marketplace were conducted, and stakeholders were consulted to define the key objectives and content of Foodbot Factory. Dietitian and teacher stakeholders identified priority age groups and learning objectives. Using a quasi-experimental mixed method design guided by the Iterative Convergent Design for Mobile Health Usability Testing approach, five app user testing sessions were conducted among students (ages 9-12 years). During gameplay, engagement and usability were assessed via direct observations with a semistructured form. After gameplay, qualitative interviews and questionnaires were used to assess user satisfaction, engagement, usability, and knowledge gained.

Results: The environmental scan data revealed that few evidence-based nutrition education apps existed for children. A literature search identified key nutrients of concern for Canadian children and techniques that could be incorporated into the app to engage users in learning. Foodbot Factory included characters ( 2 scientists and Foodbots) who initiate fun and engaging dialogue and challenges (minigames), with storylines incorporating healthy eating messages that align with the established learning objectives. A total of five modules were developed: drinks, vegetables and fruit, grain foods, animal protein foods, and plant protein foods. Seven behavior change techniques and three unique gamified components were integrated into the app. Data from each user testing session were used to inform and optimize the next app iteration. The final user testing session demonstrated that participants agreed that they wanted to play Foodbot Factory again $(12 / 17,71 \%)$, that the app is easy to use $(12 / 17,71 \%)$ and fun $(14 / 17$, $88 \%)$, and that the app goals were clearly presented $(15 / 17,94 \%)$.

Conclusions: Foodbot Factory is an engaging and educational mHealth intervention for the Canadian public that is grounded in evidence and developed by an interdisciplinary team of experts. The use of an iterative development approach is a demonstrated 
method to improve engagement, satisfaction, and usability with each iteration. Children find Foodbot Factory to be fun and easy to use, and can engage children in learning about nutrition.

(JMIR Form Res 2020;4(4):e15534) doi: 10.2196/15534

\section{KEYWORDS}

mHealth; children; child nutrition sciences; mobile apps; health education

\section{Introduction}

\section{Background}

Poor diet quality is a leading risk factor for chronic disease, such that the risk of morbidity and mortality from a low-quality diet now surpasses the risk associated with tobacco exposure [1]. Globally, the greatest dietary risk factors are high intakes of sodium and low intakes of whole grains, fruits, and vegetables [1]. In Canada, $92 \%$ of children consume excess sodium, and on average, children do not consume the recommended servings of whole grains, vegetables, and fruits, findings that are consistent with most other developed countries [2,3]. These dietary risk factors are extremely relevant for children as they require high-quality diets for growth, development, and academic success [4]. Healthy eating behaviors are established during childhood; therefore, it is important to optimize the adoption of these behaviors early in life so that they will be more likely to be sustained into adulthood [5].

Mobile health (mHealth) innovations present novel opportunities to address public health challenges [6]. Systematic reviews and individual studies demonstrate that mHealth interventions improve a variety of dietary and health-related outcomes, such as nutrition knowledge, overall eating patterns, fruit and vegetable intake, intake of nutrients of public health concern (ie, dietary sodium), body weight, blood pressure, and blood cholesterol levels across various populations and age groups, including children and adolescents [7-14]. In addition to health benefits, mHealth interventions are a promising and an innovative way to facilitate nutrition education as children and adolescents increasingly have access to mobile devices at home and school. In Canada, $47 \%$ of children aged 0 to 11 years and $80 \%$ of adolescents aged 12 to 17 years own a mobile device [15]. However, few evidence-based mHealth nutrition apps for children are publicly available on the app marketplace [16], and there are currently no known apps available to support educators in facilitating nutrition education in the classroom or clinic settings $[17,18]$. These data point to a significant gap and an opportunity to address an important public health issue in using evidence-based and engaging mHealth nutrition interventions as a way to engage children in learning about healthy eating.

\section{Objective}

The aim of this study was to describe the iterative design, development, and testing of an engaging, evidence-based
mHealth nutrition education app, Foodbot Factory. The Foodbot Factory app was developed as a public health intervention to increase the knowledge and awareness about food and nutrition among healthy children and was designed for use at home and in school. This gamified mHealth app was developed by an interdisciplinary team for children aged 9 to 12 years. The overarching objective of Foodbot Factory is to improve food and nutrition knowledge among children.

\section{Methods}

\section{Study Design}

An interdisciplinary team of experts was formed to develop Foodbot Factory. This team included experts in nutrition science, behavioral interventions, education, pedagogy and technology, and game design. The team also collaborated with the Office of Nutrition Policy and Promotion at Health Canada who are responsible for improving the health of Canadians through the implementation of nutrition policies and programs.

Foodbot Factory development and testing methodologies were guided by the Obesity-Related Behavioral Intervention Trials (ORBIT) model, which is used for developing behavioral interventions for chronic disease prevention and management (Figure 1) [19]. This model is useful for the development of complex interventions as goals and milestones are established for each phase, and developers are encouraged to revisit previous phases to improve the intervention based on new evidence [19]. The ORBIT model also promotes the integration of behavioral and social sciences research by requiring that the design phase is informed by the latest research, ensuring that high-quality evidence is incorporated into the intervention. The ORBIT model was chosen because it emphasizes the process of developing a behavioral intervention as opposed to the actual content, which will vary across disciplines, populations, and scenarios. It was further considered ideal in the development of Foodbot Factory as it emphasizes a data-driven iterative approach to optimize successive iterations of the intervention, so that the intervention will effectively achieve its intended objectives. In addition, the ORBIT model is highly complementary to frameworks used by game developers, such as the Design, Play, and Experience framework [20]. This paper has presented the development and evaluation of Foodbot Factory over three phases of the ORBIT model-Discovery, Phase Ia: Define, and Phase Ib: Refine[19]. 
Figure 1. Obesity-Related Behavioral Intervention Trial model.

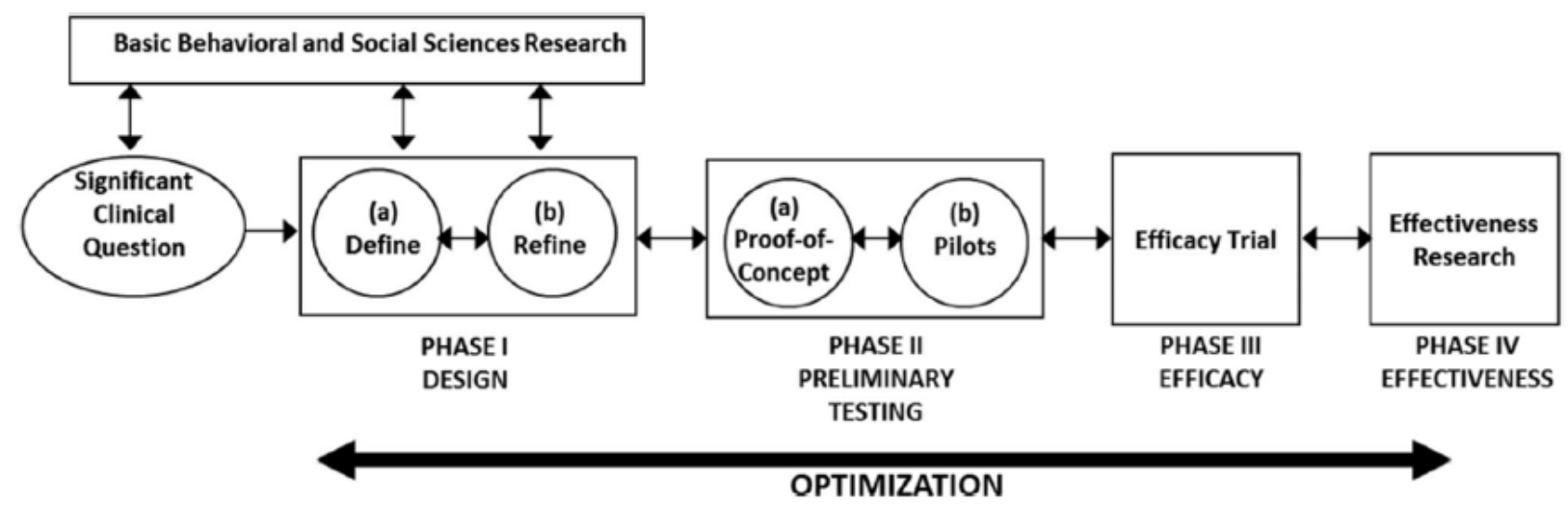

\section{Discovery Phase}

During the Discovery phase, the central research question was defined, and educational and behavioral strategies to effectively engage children in learning about nutrition were identified [19]. This phase of development involved background research in behavioral sciences, pedagogy, mHealth app development, and nutritional sciences to identify important points for the intervention and effective methods and techniques for delivery. Background research included a systematic literature search of the PubMed database, conducted in October 2017, to identify peer-reviewed research of mHealth nutrition interventions targeted at a child population. A scoping review was also conducted to identify relevant systematic reviews and literature on the dietary habits of Canadian children. An additional environmental scan of existing mHealth resources was conducted to establish a baseline understanding of the learning tools available for nutrition education [16].

\section{Phase I: Design}

The overall goal of Phase I: Design was to identify the essential features of the Foodbot Factory app, which included identifying the goals and structure and tinkering with the nutrition content and educational strategies to refine and improve upon it [19]. This phase required insights on the nutrition education priorities for the target audience, alignment with behavioral theory, and iterative development and testing of Foodbot Factory.

\section{Phase Ia: Define}

For the Define phase, three key components were outlined based on the Discovery Phase findings: nutrition content, gamification, and behavior change techniques (BCTs) [19]. Key stakeholders were consulted from February to May 2017 to refine the (1) target age group, (2) isolate the highest priority nutrition education issues, and (3) identify the support needed to implement nutrition curricula. Nutrition-focused stakeholders included public health dietitians who were contacted through Dietitians of Canada, Ontario Dietitians in Public Health, and Health Canada. We also consulted with teachers at a local school board. Stakeholders provided input via a Web-based questionnaire that consisted of 22 items on 7-point Likert scale questions. Open-ended questions were also included to capture additional narrative feedback.
Specific learning objectives incorporating the curriculum and public health priorities were defined based on data and feedback from stakeholders. Considering published evidence on best practices for mHealth apps targeted at children, it was decided that learner engagement with the educational content in Foodbot Factory would be enhanced by including (1) gamification, which refers to the application of game design elements to engage and motivate users [21], and (2) evidence-based BCTs, which are "the observable, replicable, and irreducible components of an intervention designed to alter or redirect causal processes that regulate behavior" [22]. The Foodbot Factory content was defined and redefined by the development team throughout the iterative development process, incorporating the latest scientific evidence and findings from Phase Ib user testing results.

\section{Phase Ib: Refine}

The purpose of the Refine phase is to ensure that an intervention is robust and efficient at achieving its intended objectives. Therefore, a quasi-experimental mixed method design was used to structure formal user testing sessions to allow for the examination of the user experience and impact of the intervention on learning. These outcomes were assessed with each iteration of Foodbot Factory, a method recommended by the Iterative Convergent Design for Mobile Health Usability Testing approach $[19,23]$. This mixed method approach provided the development team with rich multi-faceted data on the users' experience, which were then used to inform subsequent iterations of the intervention. The Refine phase included five iterative user testing sessions with the target audience. As various aspects of Foodbot Factory were defined in Phase Ia, they were tested with users and refined in Phase $I b$. Throughout the development process, successive iterations of Foodbot Factory moved between Phases $I a$ and $I b$ as the app components were optimized for usability and satisfaction to facilitate engagement in learning.

The five iterative user testing sessions were conducted with student participants in grades 4 to 6 (aged 9-12 years) from a local school board and a science and technology summer camp at Ontario Tech University. User testing sessions were approximately 20 to $30 \mathrm{~min}$ in duration and began with an explanation of the study procedures, followed by the collection of informed assent from participants and brief instructions on how to use Foodbot Factory. The participants tested the app on an Apple iPad (iOS 12) or a Lenovo tablet (Android 8.1.0) for 
$10 \mathrm{~min}$, followed by interviews and questionnaires for another 10 min. Each student had their own device; however, participants were able to discuss the app with their peers as they played. Parental consent was obtained before user testing sessions through letters of information and consent forms that were sent home with students before the study. No compensation was provided for parents, students, teachers, or camp counsellors.

The user testing sessions assessed satisfaction, engagement, knowledge, and usability, which were chosen to reflect the core features and components necessary for the app to be successful. Satisfaction refers to the user's subjective experience with Foodbot Factory and the appropriateness and suitability of the platform and content for the target audience. Engagement refers to how the target audience interacted with the app, (ie, found the app enjoyable and wanted to play again). Knowledge refers to how well Foodbot Factory supported the target audience's acquisition of information about healthy eating. Usability refers to the technical aspects of the app, (ie, easy to use and navigate and clear presentation of content). These metrics were assessed using direct observations, interviews, and questionnaires.

During gameplay, direct observations were used by the research and development team to evaluate usability and engagement with the app. Direct observations included recording notes and completing an internally developed semistructured form where the rater recorded comments about usability and engagement. At this time, perceived engagement with the app dialogue was also rated on a 5-point Likert scale. After gameplay, one-on-one semistructured interviews were conducted with the student participants. The interviews included five questions to assess user satisfaction and knowledge acquisition, with a focus on obtaining feedback for the next iteration of the app, rather than a formal evaluation of learning. Interview guides were created by the development team. The interviews were not audio- or video-recorded, rather verbatim notes were taken. The verbatim notes were reviewed by the development team to identify priority areas for improvement in the next app iteration. Answers to questions regarding nutrition knowledge were summarized based on student responses and have been presented as frequencies. Finally, participants also completed an 8-item (5-point Likert scale) questionnaire to assess engagement and usability. Questions were adapted from a validated questionnaire for adults as no known validated questionnaire was available to assess game engagement in children [24].

Categorical data are reported as frequencies and percentages, and continuous data are reported as means and standard deviations. Likert scale responses ranged from strongly disagree to strongly agree. For the analysis, strongly disagree and disagree were pooled to reflect disagreement with a questionnaire item and strongly agree and agree were pooled to reflect agreement with a questionnaire item. An unpaired 2-tailed $t$ test was used to conduct post hoc analyses that compared user satisfaction between boy and girl participants. SPSS (v 25) was used for the statistical analysis. A $P$ value of .05 was considered statistically significant.

Parental consent and child assent were obtained before the user testing sessions. In total, five iterative user testing sessions were conducted. An ethics board approval was obtained from both Ontario Tech University and the Durham Catholic District School Board (file numbers: 14426 and 14879).

\section{Results}

\section{Discovery}

The development process for Foodbot Factory began in October 2017, and the research presented in this paper was completed in December 2018. The design process of Foodbot Factory was facilitated by an interdisciplinary team who met on a weekly basis to propose ideas, define specific app content, review user testing results, and subsequently refine the app content.

A scoping review identified foods and nutrients of concern for this population and found that the average Canadian child has an inadequate intake of fiber and an excessive intake of saturated fat, sugar, and sodium [25]. Canadian children also consume inadequate amounts of vegetables, fruits, and whole grains and acquire $30 \%$ of daily sugar calories from beverages containing free sugars; therefore, the education of these foods and nutrients was considered a priority for the app $[3,26]$.

Existing systematic reviews of mHealth dietary interventions for children and adolescents were identified. These studies indicated that nutrition knowledge acquisition, nutrition-related behaviors, and nutrition-related health outcomes improve with mHealth interventions [7,9], and they highlighted the strengths of gamification as a strategy to implement for child nutrition mHealth apps [27,28]. An additional systematic search, conducted by the Foodbot Factory research and development team, focused on identifying other strategies demonstrated to engage children in learning or behavior change through mHealth nutrition apps [10,11,29-35]. Gamification was implemented in two articles and was found to clearly engage children in learning and improving their nutrition knowledge and behaviors and health outcomes [10,31]. In addition, the use of BCTs was also identified as a replicable and potentially effective approach to include in the mHealth app [36]. There was minimal evidence on the most effective BCTs to incorporate for our target audience to achieve the goals of Foodbot Factory. Therefore, the development team hypothesized which BCTs would be most effective at facilitating learning among the target audience and evaluated the user experience and learning throughout the iterative development process.

An environmental scan of the app marketplace identified 249 mobile food apps targeted at children [16,37]; however, very few were of high quality, as scored by the Mobile App Rating Scale [38]. Furthermore, gamified apps were more likely to display high-sodium and high-sugar foods and received a higher number of downloads compared with nongamified apps. These results identified gaps in the public app marketplace, where food games are popular with children but are not aligned with the existing dietary recommendations [16,37].

The research conducted in this phase identified research gaps in the development of child nutrition mHealth apps; however, positive findings from the available literature indicated that gamified mHealth apps are a promising avenue to pursue for education. Furthermore, evidence gathered in this phase 
demonstrated that mHealth nutrition apps are engaging and can be accessed by the majority of the target population because of the ubiquity of mobile technology in Canada [39]. The Discovery phase led to the research question: "Can a mHealth nutrition education app improve nutrition knowledge in children aged 9-12?" This question defined the focus of Foodbot Factory to improve users' nutrition knowledge related to foods and nutrients of public health concern $[3,25]$. With the central research question and strategy identified, the development of Foodbot Factory proceeded to Phase Ia [19].

\section{Phase Ia: Define}

Dietitian and teacher stakeholders $(n=21)$ reported their perceived priorities in relation to the target audience and learning objectives for the app: $81 \%(17 / 21)$ ranked grades 7 to 8 as the first priority age group and 86\% (18/21) ranked grades 5 to 6 as the second priority age group for a nutrition education app. The interdisciplinary app development team decided to target students in grades 4 to 6 (aged 9-12 years) for the app as it was believed this age group would be more interested in a gamified nutrition app compared with older students. Overall, $86 \%$ $(18 / 21)$ of stakeholders agreed that increasing water consumption and decreasing sugary beverage consumption was important for this age group, and 57\% (12/21) of them also agreed that understanding the nutritional value of foods was important.

In alignment with stakeholder feedback, the app was designed to meet the 2018 Ontario Grade 4 Health and Physical Education Curriculum expectations that students should "identify the key nutrients (eg, fat, carbohydrates, protein, vitamins, minerals) provided by foods and beverages, and describe their importance for growth, health, learning, and physical performance" [40]. This expectation also aligns with the health curriculum expectations from other Canadian provinces and territories, providing teachers across the country with a mobile tool to aid nutrition education in the classroom $[41,42]$.

The goal of Foodbot Factory is to improve nutrition knowledge, a component of food skills that has been identified as a gap in the ability of Canadian youth to make healthy eating choices [43]. Although knowledge is often insufficient to initiate dietary behavior change, it is necessary for individuals to change their behavior and is associated with better diet quality in adolescents [44]. Furthermore, the most recent version of Canada's Food Guide (CFG), the leading government resource developed by Health Canada for nutrition guidance, has been disseminated entirely through digital platforms [45]. The CFG is a core component of the school curriculum across Canada. However, to date no tailored resources, messaging, or tools have been created for children and teachers, highlighting a significant gap in nutrition education in Canada [40-42]. As our target audience of 9- to 12-year-old moves into adolescence, they will exercise greater autonomy in their eating decisions. It is hypothesized that the nutrition knowledge obtained from Foodbot Factory will empower student users to make healthier dietary choices. Therefore, the goal of this app is to provide the baseline knowledge required to make informed healthy eating choices.

\section{Nutrition Content}

To align Foodbot Factory with the latest dietary guidelines, the development team consulted with Health Canada to ensure the app's content aligned with the messages in the new 2019 CFG recommendations. The nutrition content in Foodbot Factory is structured into five modules, corresponding to the CFG food groups and linking to specific learning objectives [45]. Specific learning objectives were developed for the foods and nutrients relevant for each food grouping, as detailed in Table 1 (Multimedia Appendix 1).

Table 1. Foodbot Factory modules, nutrients of concern, and learning objectives.

\begin{tabular}{|c|c|c|}
\hline Level (food grouping) & Nutrients of concern included & Module learning objectives \\
\hline Drinks & Sugar & $\begin{array}{l}\text { - } \quad \text { Recall the best beverage choice for staying hydrated } \\
\text { - } \quad \text { Describe the health effects of different types of beverages } \\
\text { - } \quad \text { Recall different types of sugary drinks }\end{array}$ \\
\hline Grain foods & Fiber & $\begin{array}{l}\text { Explain the nutritional differences between whole grain and refined grain } \\
\text { products } \\
\text { - } \quad \text { Recall the components of the grain kernel and how grains are refined } \\
\text { - } \quad \text { Describe why consuming fiber is important for health }\end{array}$ \\
\hline Vegetables and fruits & Fiber, vitamins, and minerals & $\begin{array}{l}\text { - Recall the amount of vegetables and fruits that should be consumed with a } \\
\text { meal } \\
\text { - } \quad \text { Explain why vegetables and fruits are a healthy choice } \\
\text { - Describe which forms of vegetables and fruit are healthiest to consume (ie, } \\
\text { canned, frozen, and juice) }\end{array}$ \\
\hline Animal protein foods & Protein, saturated fat, and sodium & $\begin{array}{l}\text { - Recall that some fats are healthy (unsaturated fats) and unhealthy (saturated } \\
\text { fats) } \\
\text { - } \quad \text { Describe the health effects of excess dietary saturated fat and sodium. } \\
\text { - } \quad \text { Explain why processed meats should be consumed less often } \\
\text { - } \\
\text { Describe why fish are a healthy choice }\end{array}$ \\
\hline Plant protein foods & Protein and fiber & $\begin{array}{l}\text { - Describe what foods are plant protein foods and why they are a healthy choice } \\
\text { - } \quad \text { Recall that plant protein foods contain fiber }\end{array}$ \\
\hline
\end{tabular}




\section{Gamification}

The app included three main gamified elements to enhance user interactions, engagement, and motivation to play: quizzes, catching food, and sorting food. Foodbot Factory is a story-based app set in a fictional town where residents have

Figure 2. Foodbot Factory screenshots.
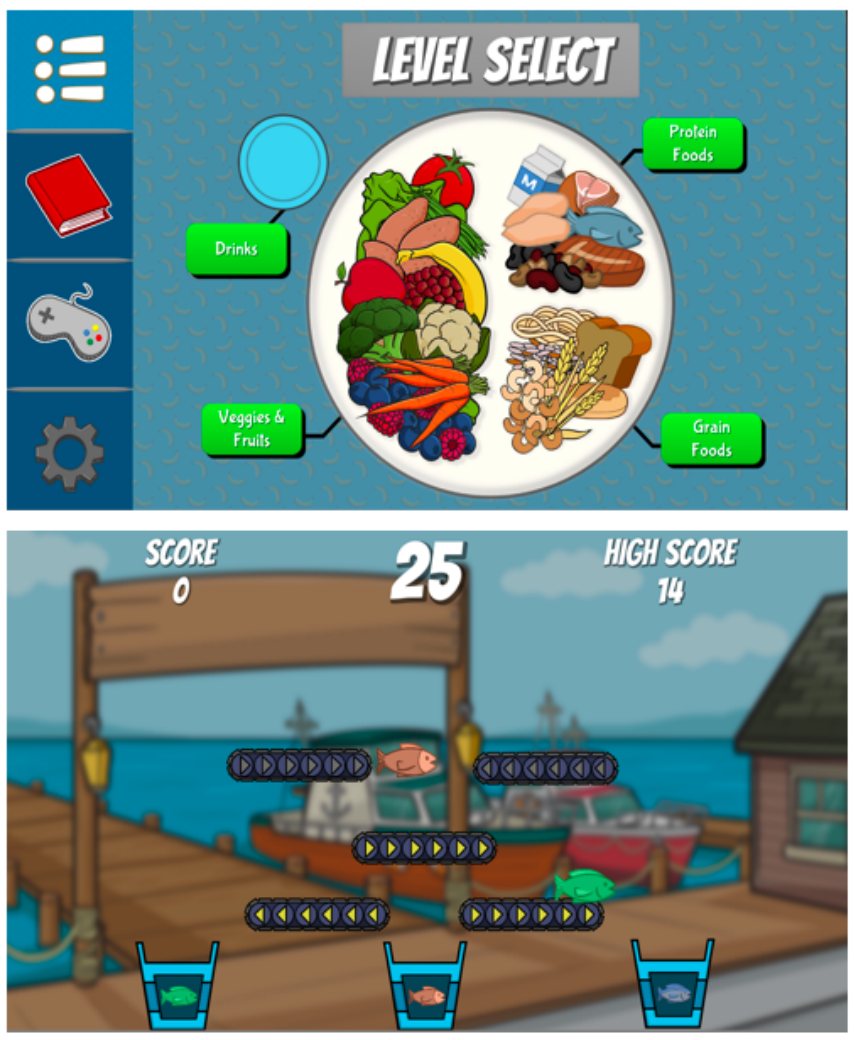

Each of the five modules has four unique components: dialogue, gameplay, food quizzes, and food logs (Figure 3). Dialogue communicates the nutrition content and allows for game character development, incorporating elements of humor and banter. A total of three modules contain additional interactive dialogue allowing for the users' choice in the content explored. A Flesch Formula score of 88.9 indicates that the dialogue is easy to read and appropriate for grade 4 readers [46]. Gameplay opportunities are provided intermittently during each module. Gameplay involves collecting or sorting a variety of food items and is varied across the five modules to limit repetition. Food nutrition robots (Foodbots) to help them make dietary decisions. The storyline is driven by two nutrition scientists, Robbie and Rebecca, who guide the user on a healthy eating adventure that begins when one of the Foodbots experiences mechanical failure (Figure 2 and Multimedia Appendix 2).
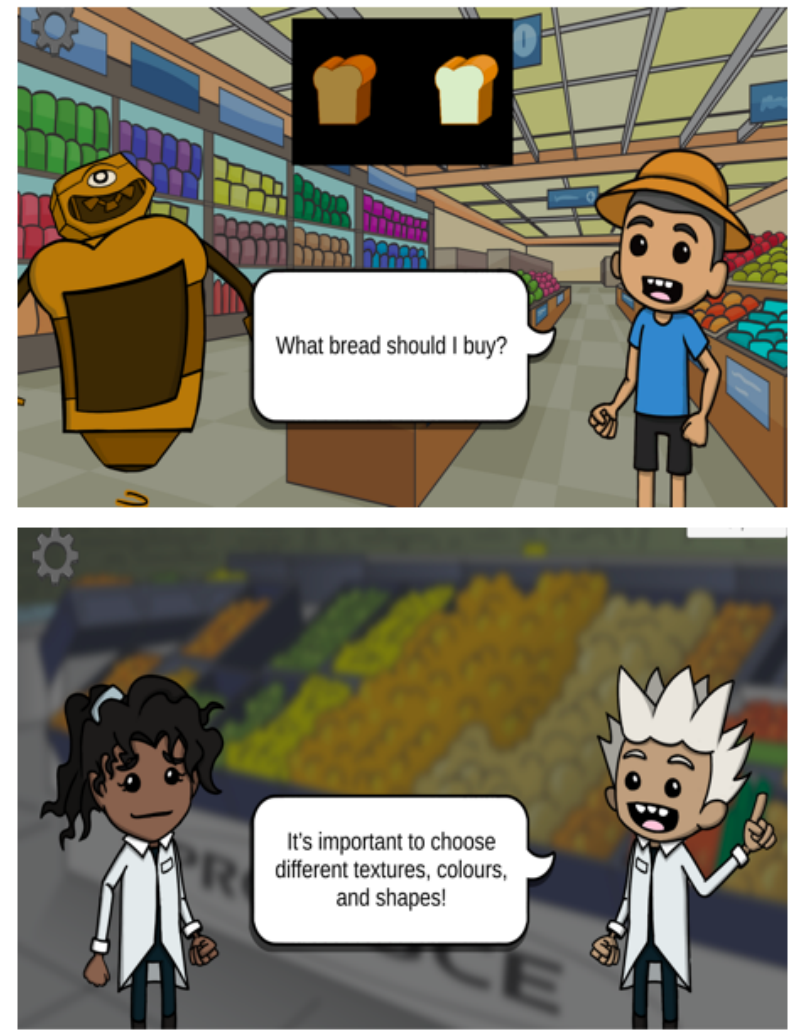

Figure 3. Foodbot Factory game flow diagram for Drinks module.

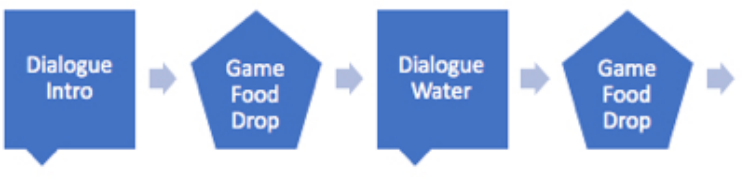

Foodbot Factory employs multiple gamification characteristics, as defined by the Taxonomy of Gamification Concepts for Health Apps and highlighted in Multimedia Appendix 3 [47]. In summary, the app utilizes mediated communication where information is delivered through a guided storyline. Rewards are received within the app, and there is no competition with other players or opportunities for collaboration. As Foodbot Factory is educational, the content focuses on learning quizzes conclude each module, allowing the users to self-assess their learning. The quizzes allow for self-correction for incorrect responses. The quizzes are interactive, requiring the user to help game characters make healthy eating decisions. The interactive quizzes were designed to simulate real-world dietary choices, which may increase the user's confidence in making real-life healthy eating decisions. The food $\log$ (a compendium of foods introduced in the app) is the final component of each module. The food log provides a platform for the user to enhance and expand their learning and explore food nutrition facts, reinforcing information presented in the module. objectives and does not include goal setting, eg, setting a goal for daily water intake. Users receive positive and negative reinforcement during gameplay. Negative reinforcement occurs during gamified components when users do not sort or catch the correct foods or when a question in the food quiz is answered incorrectly. The persuasive intent of Foodbot Factory is to positively change user's attitudes and knowledge regarding healthy eating. 


\section{Behavior Change Techniques}

BCTs were incorporated into the app to illustrate how the knowledge gained can be applied to actual dietary decisions and increase self-efficacy around these decisions. The main BCT categories integrated throughout Foodbot Factory are feedback and monitoring, social support, shaping knowledge, natural consequences, and reward and threat [22]. In total, Foodbot Factory utilizes seven BCTs across the game (Table
2) [22]. In each module, users have the opportunity to self-assess their knowledge by helping game characters make dietary decisions. The users are then provided with feedback on the accuracy of those dietary decisions. Users also learn about the natural health consequences that result from consuming certain foods and nutrients. At the end of each module, users are rewarded by unlocking new food items in the food log, where they can review additional nutrition information.

Table 2. Behavior change techniques implemented in Foodbot Factory.

\begin{tabular}{|c|c|}
\hline Module & Behavior change techniques implemented \\
\hline \multirow[t]{5}{*}{ Drinks } & 2.2 Feedback on behavior \\
\hline & 4.1 Instruction on how to perform the behavior \\
\hline & 4.2 Information about antecedents \\
\hline & 5.1 Information about health consequences \\
\hline & 10.3 Nonspecific reward \\
\hline \multirow[t]{4}{*}{ Grain foods } & 2.2 Feedback on behavior \\
\hline & 4.1 Instruction on how to perform the behavior \\
\hline & 5.1 Information about health consequences \\
\hline & 10.3 Nonspecific reward \\
\hline \multirow[t]{6}{*}{ Vegetables and fruits } & 2.2 Feedback on behavior \\
\hline & 3.1 Social support (unspecified) \\
\hline & 4.1 Instruction on how to perform the behavior \\
\hline & 4.2 Information about antecedents \\
\hline & 5.1 Information about health consequences \\
\hline & 10.3 Nonspecific reward \\
\hline \multirow[t]{5}{*}{ Plant protein foods } & 2.2 Feedback on behavior \\
\hline & 4.1 Instruction on how to perform the behavior \\
\hline & 5.1 Information about health consequences \\
\hline & 6.1 Demonstration of behavior \\
\hline & 10.3 Nonspecific reward \\
\hline \multirow[t]{4}{*}{ Animal protein foods } & 2.2 Feedback on behavior \\
\hline & 4.1 Instruction on how to perform the behavior \\
\hline & 5.1 Information about health consequences \\
\hline & 10.3 Nonspecific reward \\
\hline
\end{tabular}

\section{Phase Ib: Refine}

\section{User Testing Session 1: Drinks and Grain Foods}

The first user testing session assessing the drinks and grain foods modules occurred with student participants in grade 5 $(8 / 12,67 \%$ male) and grade $6(10 / 18,56 \%$ male). It was observed that grade 6 students progressed through the app at a faster rate than grade 5 students and seemed less engaged and interested in the app. Overall, $83 \%(25 / 30)$ agreed that the app was fun and 83\% (25/30) agreed that the goals of the app were clear. Confusion and frustration in navigating the gameplay portion of the modules was also observed. Only 29\% (8/30) of students agreed that the robot was easy to control. Compared with male students, female students appeared to be more interested in the healthy eating content and were more likely to want to play the app again. On the basis of this feedback, the aims for the next iteration of the app were to include more explicit tutorial instructions, improve the game controls and the movement of the robot, increase the use of gamification to enhance engagement, and clearly state the goals of the modules.

\section{User Testing Session 2: Drinks}

The next iteration of Foodbot Factory was tested with grade 4 student participants (10/20, 50\% male). A direct observation revealed that students were more engaged with the dialogue and most students $(14 / 20,70 \%)$ demonstrated a high interest in reading the healthy eating content. Some students $(4 / 20,21 \%)$ showed visual frustration or confusion during game play and asked for help. Those who were confused were also observed skipping quickly through dialogue, indicating that they felt the module had too much reading. On basis of the observation, the students' ability to move the robot improved from the previous iteration. An improvement in the clarity of the app goals and the student's perceived enjoyment of the app was observed with this iteration of the app (Table 3). When students were asked about their favorite part of the game, $30 \%(6 / 20)$ identified the app characters and dialogue humor, whereas $25 \%(5 / 20)$ favored 
the food quiz gamified component and 15\% (3/20) identified learning about nutrition. Students demonstrated learning through using the app: $90 \%(18 / 20)$ of students correctly identified water as the best beverage choice and responded as follows: "Water is needed to stay hydrated."; "Water, because if you're thirsty you can stay hydrated." Some students provided extended commentary, stating " $60 \%$ of your body is water." and "I learned even more about having pop less." The interviews demonstrated that students understood the key healthy eating messages embedded in the app as they recalled and explained why water is the best beverage choice for health and hydration.

Table 3. Summary of quantitative data for the drinks module (sessions 1-4; session 1 occurred with students in grades 5 to 6 . Sessions 2 and 3 occurred with students in grade 4 . Session 4 occurred with students in grades 4 to 7 .)

\begin{tabular}{llll}
\hline User testing session & Strongly disagree and disagree, $\mathrm{n}(\%)$ & Neutral, $\mathrm{n}(\%)$ & Strongly agree and agree, $\mathrm{n}(\%)$ \\
\hline The app was fun & & $2(7)$ & $25(83)$ \\
Session $1(\mathrm{~N}=30)$ & $3(10)$ & $0(0)$ & $18(95)$ \\
Session $2(\mathrm{~N}=20)$ & $1(5)$ & $1(7)$ & $13(93)$ \\
Session $3(\mathrm{~N}=14)$ & $0(0)$ & $2(10)$ & $19(90)$ \\
Session $4(\mathrm{~N}=21)$ & $0(0)$ & & $25(83)$ \\
The goals of the app were clear & & $1(3)$ & $19(95)$ \\
Session 1 & $4(13)$ & $0(0)$ & $12(86)$ \\
Session 2 & $1(5)$ & $1(7)$ & $20(95)$ \\
Session 3 & $1(7)$ & $1(5)$ & \\
Session 4 & $0(0)$ & & \\
\hline
\end{tabular}

\section{User Testing Session 3: Drinks}

The next iteration of the drinks module was tested with grade 4 student participants (12/14, 86\% male). Most students continued to agree or strongly agree with the statements that the app was fun and the goals of the app were clear (Table 3). The major modification to this iteration was the addition of two gamified food catches to introduce more gameplay, which the team hypothesized would increase engagement and interest in the app. However, more students skipped most of the dialogue compared with session 2 (Table 4). A total of 6 students demonstrated visual frustration or confusion, which was related to the food catch, as students had skipped through the added tutorial and did not understand what to catch to obtain points. Fewer students provided the correct answer when prompted to choose which drink is the best choice for health, with 57\% (8/14) stating water. This may suggest that gamified components need to be carefully incorporated so that educational messages are not lost. Conversely, among the $36 \%(5 / 14)$ of students who incorrectly stated that milk was the best choice, many were able to express their knowledge of water during the interview. The high positive response of milk may reflect students' taste preference for milk over water or baseline knowledge from parents and care providers rather than a lack of knowledge on the importance of water for health and hydration.

Table 4. Summary of observational data for sessions 2 to 5 .

\begin{tabular}{lll}
\hline User testing session & High reading interest ${ }^{\mathrm{a}}, \mathrm{n}(\%)$ & Skipped most of the dialogue, $\mathrm{n}(\%)$ \\
\hline Session $2(\mathrm{~N}=20)$ & $14(70)$ & $2(10)$ \\
Session $3(\mathrm{~N}=14)$ & $7(51)$ & $2(14)$ \\
Session $4(\mathrm{~N}=21)$ & $13(60)$ & $2(10)$ \\
Session $5(\mathrm{~N}=17)$ & $13(75)$ & $2(13)$ \\
\hline
\end{tabular}

${ }^{\text {a } H i g h ~ r e a d i n g ~ i n t e r e s t ~ w a s ~ d e f i n e d ~ a s ~ a n ~ o b s e r v a t i o n a l ~ r a t i n g ~ o f ~} 4$ or 5 on a 5-point Likert scale assessing engagement with dialogue content. Skipping dialogue was assessed via an observational note with options of none, some, and most. Students who skipped most of the dialogue were observed flipping quickly through the dialogue and not reading the majority of the content.

\section{User Testing Session 4: Drinks and Grain Foods}

The next testing session occurred with summer camp student participants at Ontario Tech University (14/21, 66\% male; grades 4-6). The drinks module was unmodified from session 3 . The grain foods module was modified to include a new interactive component to teach about different parts of the grain kernel and play an additional food sort minigame to increase the variety between the gamified portions of each module. It was hypothesized that engagement would increase by including a variety of interactive components. Observations during gameplay were similar to previous sessions; however, some students appeared to disengage, ie, appearing bored, after playing more than one module. This may explain why observational data showed a slight decline in engagement compared with sessions 2 and 3 where only one app module was tested (Table 4). As in previous sessions, students connected with the game characters and humorous dialogue, with 2 
students commenting the following: "That was really fun!" In this testing session, no students showed visual frustration or confusion, potentially indicating that the usability of the game and clarity of instructions had improved.

Knowledge gained by using Foodbot Factory improved from previous sessions. For the drinks module, all students (21/21) replied that water is the best for quenching thirst, with students recognizing that "You need it [water] to survive and stay hydrated" and " $60 \%$ of the body is made of water." Students also conveyed their knowledge of milk and sugary drinks. Students' comments included the following: "Milk has calcium and Vitamin D and makes bones grow bigger and stronger" and "Pop is a treat like chocolate. You get cavities from the sugar." For the grain foods module, $70 \%(15 / 21)$ of students recalled that whole grain bread has more fiber than white bread, with students stating "Whole grain bread has more fiber and is better for you than white bread because of fiber" and "White bread has less fiber because they remove the bran and the germ." On average, students were able to fulfill the learning objectives for both the drinks and grain foods modules. Importantly, there were considerable improvements on two key metrics of concern. Overall, 90\% (19/21) of students agreed with the statement "the app was fun" and 95\% (20/21) agreed "the goals of the app were clear" (Table 3). Although observational data suggest that students may disengage when playing multiple modules in one sitting, the self-reported questionnaire data confirm that students found the game engaging and usable.

\section{User Testing Session 5: Vegetables and Fruits and Protein Foods}

In this last user testing session among grade 4 student participants $(9 / 17,55 \%$ male), the first iterations of the vegetables and fruits module or the protein foods module were tested. On the basis of the iterative feedback and lessons learned from previous testing sessions, these modules included multiple interactive components. For example, interactive components allowed students to choose the vegetables and fruits to learn about or to cook pasta, and there was added variation between the food sort and food catch minigames.

Similarly, high levels of engagement as seen in previous user testing sessions were observed (Table 4). Among those who played the vegetables and fruits module $(\mathrm{N}=8), 75 \%(6 / 8)$ of students recalled a key healthy eating message, with one student stating "They [vegetables \& fruits] have lots of vitamins and minerals" and another stating "Most of the stuff [nutrients] helps your body and when you eat it, it helps your body work." By contrast, only $55 \%(5 / 9)$ of students who played the protein foods module $(\mathrm{N}=9)$ were able to recall a key healthy eating message. The team concluded that this first iteration of the protein foods module had an ambitious number of key messages and learning outcomes. Therefore, the protein foods module was divided into animal protein foods and plant protein foods to enhance the focus and clarity of healthy eating messages and improve students' ability to meet the learning objectives. Overall, the majority of users still found the modules to be fun, with clear goals, easy to use, and easy to read (Table 5). A total of $71 \%(12 / 17)$ of students agreed with the statement "I want to keep playing," indicating that Foodbot Factory is an engaging and acceptable way for students to learn about food, nutrition, and healthy eating (Table 5).

Table 5. Summary of quantitative data for user testing session $5(\mathrm{~N}=17)$

\begin{tabular}{llll}
\hline Question & Strongly disagree and disagree, $\mathrm{n}(\%)$ & Neutral, $\mathrm{n}(\%)$ & Strongly agree and agree, $\mathrm{n}(\%)$ \\
\hline The goals of the app are clear & $1(6)$ & $0(0)$ & $16(94)$ \\
The app was easy to use & $1(6)$ & $4(24)$ & $12(71)$ \\
The words in the app are easy to read & $1(6)$ & $4(24)$ & $12(71)$ \\
I want to keep playing & $0(0)$ & $5(29)$ & $12(71)$ \\
\hline
\end{tabular}

\section{Subgroup Analyses}

Differences in engagement between male and female student participants were observed from session 1, and it was hypothesized that female students were more engaged with the app than male students. The subgroup analysis (52/87, 60\% male) indicated that female students were significantly more likely than male students to agree that they wanted to keep playing $(29 / 35,83 \%$ vs $37 / 52,71 \% ; P=.03)$. Trends indicate that female students tended to agree that the app was fun $(33 / 35$, $97 \%$ vs $45 / 52,86 \% ; P=.11)$ and tended to disagree that they were bored $(28 / 35,82 \%$ vs $39 / 52,75 \% ; P=.09)$ compared with male students; however, these differences were not statistically significant.

To address the differences in engagement between male and female students, the development team made significant efforts to enhance overall engagement with each iteration of Foodbot
Factory by further incorporating games and humor as a strategy to better appeal to male students. A voiceover was also added to the app to enhance overall engagement and make the content more accessible for those who may have difficulty reading. Although female students tended to show higher levels of engagement compared with male students, an overall high proportion of male students still found the app fun, and they demonstrated an interest and ability to learn through gameplay, as evidenced by qualitative feedback and observation.

\section{Discussion}

\section{Principal Findings}

The iterative development and evaluation of Foodbot Factory has led to the creation of an evidence-based and engaging mHealth app to help Canadian children learn about healthy eating and nutrition. The interdisciplinary team of experts in 
nutrition, education, and game design, in collaboration with policymakers (Health Canada), ensured that the app is consistent with the latest nutrition recommendations, incorporated current advances in gaming and education technology, and can be easily implemented in the classroom. The multimethod user testing data demonstrate that the majority of Foodbot Factory's target audience find the app engaging and usable, providing evidence that this public health intervention can help Canadian children learn about nutrition. Foodbot Factory has undergone evaluation consistent with Phase I: Design in the ORBIT model and is currently being evaluated in a randomized controlled trial as a part of Phase 2: Preliminary Evaluation [19]. A strength of this research is the use of an interdisciplinary team of experts to facilitate and participate in development. An interdisciplinary approach is not always implemented when designing electronic health and mHealth interventions [48], but it should be encouraged to ensure that the multiple disciplines involved in developing high-quality digital interventions are represented throughout the development process. Our research and development team worked effectively in a collaborative fashion through weekly scheduled meetings until the app development was fully complete. We further leveraged our strong relationships with partners across disciplines, including governments, nongovernmental organizations, and school boards, to obtain diverse expert opinions and conduct the research presented in this study.

\section{Strengths and Limitations}

In comparison with similar studies that have conducted iterative user testing methodologies to develop mHealth interventions, the research presented here has implemented significantly more iterative testing sessions with the target audience. The majority of other app development studies that report user testing often implement various stepwise iterative processes throughout development; however, many only utilize one testing session with their target audience [49-53]. The use of multiple testing sessions for Foodbot Factory is a strength of this study as it allowed the research team to improve engagement and usability of the app. Multiple testing sessions also enabled app evaluation with a larger sample size and tailored the content of the app to the diverse needs of Foodbot Factory's target audience. Finally, other studies that report on the development of mHealth interventions have not implemented multiple methods in their user testing sessions $[51,53]$. The use of multiple methods in this study provided the research team with a set of rich and comprehensive data on the user experience, increasing the efficiency and effectiveness of each successive iteration of
Foodbot Factory. The development of future mHealth apps and interventions would be best informed by iterative testing to ensure that changes implemented to each iteration meet the needs of the target audience and advance the goals of the intervention. Testing should also utilize mixed method data collection, as recommended by the Iterative Convergent Design for Mobile Health Usability Testing [23].

Although there were positive outcomes to this project, we acknowledge that there were limitations. Observation was relied on as a way to assess user engagement with app dialogue content and the rate of progression; however, these measures of user engagement could have been enhanced by collecting quantitative interapp analytic data. Factors that influence the dietary intakes of children are often beyond the control of a young child (eg, socioeconomic status, parental influence, and neighborhood food environment) [54]. However, the knowledge gained from playing Foodbot Factory can assist children in making healthier dietary decisions where possible, and the foundational knowledge may stay with the child over the long term. Testing results suggest that student participants may disengage after playing more than one module during a session and that female students may be more engaged than male students. However, these findings relay important information for implementation into the classroom setting, suggesting that learning will be optimized by using the app for short periods over several days. Foodbot Factory can be played in a flexible format, providing users with a choice in the number of modules played in a given session. The app has also been designed with multiple gamified components that vary through each module to appeal to a variety of learning and gameplay preferences. Future research with Foodbot Factory includes a randomized trial measuring its impact on nutrition knowledge and development of a knowledge translation strategy to ensure maximal reach and adoption among teachers, health professionals, and parents.

In summary, Foodbot Factory is a viable and an engaging app that has the potential to improve the nutrition knowledge of Canadian children. The app aligns with the latest dietary recommendations for Canadians and curriculum expectations for most Canadian provinces [40,45]. Foodbot Factory utilizes increasingly available technologies, providing a contemporary means for children to learn about nutrition at home and in the classroom. The knowledge gained during childhood may be sustained into the adolescent years, with the intended benefit of improving dietary intake and reducing the risk of chronic diseases associated with poor diet quality.

\section{Acknowledgments}

This study was supported by grant funding from the Ontario Ministry of Research and Innovation. The authors would like to acknowledge the hard work of the app developers, Campbell Hamilton, Rebecca Joly, and Alain Sangalang, and those who assisted with conducting our user testing sessions, Hannah Froome, Tayyib Khan, Amina Mahmood, and Amina Siddiqi. They would also like to acknowledge and thank their partners at Health Canada's Office of Nutrition Policy and Promotion, including Dr Alfred Aziz, Emily Bell, and Mabel Pang, who have supported the development of Foodbot Factory. This research would not have been possible without the generosity and support of administrators and teachers at the Durham Catholic District School Board and Dr Shelia Rhodes at the Ontario Tech Summer Camp. 


\section{Authors' Contributions}

JA and JH conceived this work. JB, RS, BK, and JA led the development of the app and established the research design. All authors participated in the iterative development process. JB led the writing of this manuscript and completed data collection and data analysis. AK created and distributed stakeholder surveys. JB, AK, RS, GW, AL, BK, and JA developed data collection tools and the user testing strategy. AK, RS, and GW assisted with data collection. All authors contributed to revising the manuscript. All authors provided the final approval for the manuscript and agreed to be accountable for its contents.

\section{Conflicts of Interest}

None declared.

\section{Multimedia Appendix 1}

Summary of the Foodbot Factory content.

[DOCX File, 11939 KB-Multimedia Appendix 1]

\section{Multimedia Appendix 2}

A Foodbot Factory gameplay video.

[MP4 File (MP4 Video), 95747 KB-Multimedia Appendix 2]

\section{Multimedia Appendix 3}

Foodbot Factory gamification characteristics.

[DOCX File, 15 KB-Multimedia Appendix 3]

\section{References}

1. GBD 2017 Diet Collaborators. Health effects of dietary risks in 195 countries, 1990-2017: a systematic analysis for the Global Burden of Disease Study 2017. Lancet 2019 May 11;393(10184):1958-1972 [FREE Full text] [doi: 10.1016/S0140-6736(19)30041-8] [Medline: 30954305]

2. Health Canada. Government of Canada. Ottawa, Ontario, Canada: Government of Canada; 2018. Sodium Intake of Canadians in 2017 URL: https://www.canada.ca/en/health-canada/services/publications/food-nutrition/sodium-intake-canadians-2017. html [accessed 2020-02-14]

3. Tugault-Lafleur CN, Black JL. Differences in the quantity and types of foods and beverages consumed by Canadians between 2004 and 2015. Nutrients 2019 Feb 28;11(3):pii: E526 [FREE Full text] [doi: 10.3390/nu11030526] [Medline: $\underline{30823448]}$

4. Basch CE. Healthier students are better learners: high-quality, strategically planned, and effectively coordinated school health programs must be a fundamental mission of schools to help close the achievement gap. J Sch Health 2011 Oct;81(10):650-662. [doi: 10.1111/j.1746-1561.2011.00640.x] [Medline: 21923878]

5. Craigie AM, Lake AA, Kelly SA, Adamson AJ, Mathers JC. Tracking of obesity-related behaviours from childhood to adulthood: a systematic review. Maturitas 2011 Nov;70(3):266-284. [doi: 10.1016/j.maturitas.2011.08.005] [Medline: 21920682]

6. World Health Organization. WHO Guideline: Recommendations on Digital Interventions for Health System Strengthening. Geneva: World Health Organization; 2019.

7. Rose T, Barker M, Maria Jacob C, Morrison L, Lawrence W, Strömmer S, et al. A systematic review of digital interventions for improving the diet and physical activity behaviors of adolescents. J Adolesc Health 2017 Dec;61(6):669-677 [FREE Full text] [doi: 10.1016/j.jadohealth.2017.05.024] [Medline: 28822682]

8. Brannon EE, Cushing CC. A systematic review: is there an app for that? Translational science of pediatric behavior change for physical activity and dietary interventions. J Pediatr Psychol 2015 May;40(4):373-384. [doi: 10.1093/jpepsy/jsu108] [Medline: 25502745]

9. Schoeppe S, Alley S, van Lippevelde W, Bray NA, Williams SL, Duncan MJ, et al. Efficacy of interventions that use apps to improve diet, physical activity and sedentary behaviour: a systematic review. Int J Behav Nutr Phys Act 2016 Dec 7;13(1):127 [FREE Full text] [doi: 10.1186/s12966-016-0454-y] [Medline: 27927218]

10. Baghaei N, Nandigam D, Casey J, Direito A, Maddison R. Diabetic Mario: designing and evaluating mobile games for diabetes education. Games Health J 2016 Aug;5(4):270-278. [doi: 10.1089/g4h.2015.0038] [Medline: 27304882]

11. de Niet J, Timman R, Bauer S, van den Akker E, Buijks H, de Klerk C, et al. The effect of a short message service maintenance treatment on body mass index and psychological well-being in overweight and obese children: a randomized controlled trial. Pediatr Obes 2012 Jun;7(3):205-219. [doi: 10.1111/j.2047-6310.2012.00048.x] [Medline: 22492669] 
12. Thompson D, Bhatt R, Vazquez I, Cullen KW, Baranowski J, Baranowski T, et al. Creating action plans in a serious video game increases and maintains child fruit-vegetable intake: a randomized controlled trial. Int J Behav Nutr Phys Act 2015 Mar 18;12:39 [FREE Full text] [doi: 10.1186/s12966-015-0199-z] [Medline: 25890060]

13. Ali SH, Luo R, Li Y, Liu X, Tang C, Zhang P. Application of mobile health technologies aimed at salt reduction: systematic review. JMIR Mhealth Uhealth 2019 Apr 17;7(4):e13250 [FREE Full text] [doi: 10.2196/13250] [Medline: 30994467]

14. Champion K, Parmenter B, McGowan C, Spring B, Wafford Q, Gardner L, et al. Effectiveness of school-based eHealth interventions to prevent multiple lifestyle risk behaviours among adolescents: a systematic review and meta-analysis. Lancet Digit Health 2019 Sep;1(5):e206-e221 [FREE Full text] [doi: 10.1016/s2589-7500(19)30088-3]

15. eMarketer. 2016 Apr 13. In Canada, Children and Teens Have an Affinity for Digital Tools URL: https://www.emarketer.com/ Article/Canada-Children-Teens-Have-Affinity-Digital-Tools/1013816 [accessed 2019-07-01]

16. Nejatinamini S, Debenham B, Prado C, Baracos VE, Chu Q, Wismer WW, et al. Canadian Nutrition Society: Scientific Abstracts from the 10th Annual Scientific Meeting / Société canadienne de nutrition: Résumés scientifiques de la 10 réunion scientifique annuelle. Appl Physiol Nutr Metab 2019 Apr;44(4 (Suppl 1)):S1-S54. [doi: 10.1139/apnm-2019-0152] [Medline: $\underline{30983410]}$

17. Dudley DA, Cotton WG, Peralta LR. Teaching approaches and strategies that promote healthy eating in primary school children: a systematic review and meta-analysis. Int J Behav Nutr Phys Act 2015 Feb 25;12:28 [FREE Full text] [doi: 10.1186/s12966-015-0182-8] [Medline: 25889098]

18. Brown JM, Savaglio R, Watson G, LeSage A, Kapralos B, Arcand J. The making of Foodbot Factory: An evidence-based mHealth nutrition education app for children. Canadian Nutrition Society: Scientific Abstracts from the 10th Annual Scientific Meeting / Société canadienne de nutrition: Résumés scientifiques de la 10 réunion scientifique annuelle 2019 Apr;44(4 (Suppl. 1)):S8. [doi: 10.1139/apnm-2019-0152] [Medline: 30983410]

19. Czajkowski SM, Powell LH, Adler N, Naar-King S, Reynolds KD, Hunter CM, et al. From ideas to efficacy: The ORBIT model for developing behavioral treatments for chronic diseases. Health Psychol 2015 Oct;34(10):971-982 [FREE Full text] [doi: 10.1037/hea0000161] [Medline: 25642841]

20. Ferdig RE. Handbook of Research on Effective Electronic Gaming in Education. Hershey, PA: Information Science Reference; 2009.

21. Zichermann G, Cunningham C. Gamification by Design: Implementing Game Mechanics in Web and Mobile Apps. First Edition. Sebastopol, Calif: O'Reilly Media; 2011.

22. Michie S, Richardson M, Johnston M, Abraham C, Francis J, Hardeman W, et al. The behavior change technique taxonomy (v1) of 93 hierarchically clustered techniques: building an international consensus for the reporting of behavior change interventions. Ann Behav Med 2013 Aug;46(1):81-95. [doi: 10.1007/s12160-013-9486-6] [Medline: 23512568]

23. Alwashmi MF, Hawboldt J, Davis E, Fetters MD. The iterative convergent design for mobile health usability testing: mixed methods approach. JMIR Mhealth Uhealth 2019 Apr 26;7(4):e11656 [FREE Full text] [doi: 10.2196/11656] [Medline: 31025951]

24. Brockmyer JH, Fox CM, Curtiss KA, McBroom E, Burkhart KM, Pidruzny JN. The development of the Game Engagement Questionnaire: A measure of engagement in video game-playing. J Exp Soc Psychol 2009;45(4):624-634. [doi: 10.1016/j.jesp.2009.02.016]

25. Health Canada. Government of Canada. Ottawa, Canada: Health Canada; 2012. Do Canadian Adolescents Meet Their Nutrient Requirements Through Food Intake Alone? Ottawa, CA URL: https://www.canada.ca/en/health-canada/services/ food-nutrition/food-nutrition-surveillance/health-nutrition-surveys/canadian-community-health-survey-cchs/ canadian-adolescents-meet-their-nutrient-requirements-through-food-intake-alone-health-canada-2012.html [accessed 2020-02-14]

26. Langlois K, Garriguet D, Gonzalez A, Sinclair S, Colapinto C. Change in total sugars consumption among Canadian children and adults. Health Rep 2019 Jan 16;30(1):10-19 [FREE Full text] [Medline: 30649778]

27. Johnson D, Deterding S, Kuhn K, Staneva A, Stoyanov S, Hides L. Gamification for health and wellbeing: A systematic review of the literature. Internet Interv 2016 Nov;6:89-106 [FREE Full text] [doi: 10.1016/j.invent.2016.10.002] [Medline: $\underline{30135818}]$

28. Dias JD, Domingues AN, Tibes CM, Zem-Mascarenhas SH, Fonseca LM. Serious games as an educational strategy to control childhood obesity: a systematic literature review1. Rev Lat Am Enfermagem 2018 Sep 3;26:e3036 [FREE Full text] [doi: 10.1590/1518-8345.2509.3036] [Medline: $\underline{\text { 30183872] }}$

29. Aflague TF, Boushey CJ, Guerrero RT, Ahmad Z, Kerr DA, Delp EJ. Feasibility and use of the mobile food record for capturing eating occasions among children ages 3-10 years in Guam. Nutrients 2015 Jun 2;7(6):4403-4415 [FREE Full text] [doi: 10.3390/nu7064403] [Medline: 26043037]

30. Nollen NL, Hutcheson T, Carlson S, Rapoff M, Goggin K, Mayfield C, et al. Development and functionality of a handheld computer program to improve fruit and vegetable intake among low-income youth. Health Educ Res 2013 Apr;28(2):249-264 [FREE Full text] [doi: 10.1093/her/cys099] [Medline: 22949499]

31. Nollen NL, Mayo MS, Carlson SE, Rapoff MA, Goggin KJ, Ellerbeck EF. Mobile technology for obesity prevention: a randomized pilot study in racial- and ethnic-minority girls. Am J Prev Med 2014 Apr;46(4):404-408 [FREE Full text] [doi: 10.1016/j.amepre.2013.12.011] [Medline: 24650843] 
32. Panizza CE, Boushey CJ, Delp EJ, Kerr DA, Lim E, Gandhi K, et al. Characterizing early adolescent plate waste using the mobile food record. Nutrients 2017 Jan 26;9(2):pii: E93 [FREE Full text] [doi: 10.3390/nu9020093] [Medline: 28134757]

33. Pedersen S, Grønhøj A, Thøgersen J. Texting your way to healthier eating? Effects of participating in a feedback intervention using text messaging on adolescents' fruit and vegetable intake. Health Educ Res 2016 Apr;31(2):171-184. [doi: 10.1093/her/cyv104] [Medline: 26850061]

34. Schiel R, Kaps A, Bieber G. Electronic health technology for the assessment of physical activity and eating habits in children and adolescents with overweight and obesity IDA. Appetite 2012 Apr;58(2):432-437. [doi: 10.1016/j.appet.2011.11.021] [Medline: 22155072]

35. Woolford SJ, Barr KL, Derry HA, Jepson CM, Clark SJ, Strecher VJ, et al. OMG do not say LOL: obese adolescents' perspectives on the content of text messages to enhance weight loss efforts. Obesity (Silver Spring) 2011 Dec;19(12):2382-2387 [FREE Full text] [doi: 10.1038/oby.2011.266] [Medline: 21869762]

36. Michie S, Abraham C, Whittington C, McAteer J, Gupta S. Effective techniques in healthy eating and physical activity interventions: a meta-regression. Health Psychol 2009 Nov;28(6):690-701. [doi: 10.1037/a0016136] [Medline: 19916637]

37. Brown JM, Siddiqi A, Froome H, Arcand J. What's cooking? A content and quality analysis of food preparation mobile applications (P16-050-19). Curr Dev Nutr 2019 Jun;3(Supplement_1). [doi: 10.1093/cdn/nzz050.p16-050-19]

38. Stoyanov SR, Hides L, Kavanagh DJ, Zelenko O, Tjondronegoro D, Mani M. Mobile app rating scale: a new tool for assessing the quality of health mobile apps. JMIR Mhealth Uhealth 2015 Mar 11;3(1):e27 [FREE Full text] [doi: 10.2196/mhealth.3422] [Medline: 25760773]

39. Tate EB, Spruijt-Metz D, O'Reilly G, Jordan-Marsh M, Gotsis M, Pentz MA, et al. mHealth approaches to child obesity prevention: successes, unique challenges, and next directions. Transl Behav Med 2013 Dec;3(4):406-415 [FREE Full text] [doi: 10.1007/s13142-013-0222-3] [Medline: 24294329]

40. Ontario Ministry of Education. The Ontario Curriculum: Health and Physical Education. Toronto, Ontario: Queen's Printer for Ontario; 2019.

41. British Columbia Ministry of Education. BC's New Curriculum. Victoria, BC: Government of British Columbia; 2016. Physical and Health Education 4 URL: https://curriculum.gov.bc.ca/curriculum/physical-health-education/4 [accessed 2020-02-02]

42. Saskatchewan Ministry of Education. Edonline. 2010. Saskatchewan Curriculum URL: https://www.edonline.sk.ca/webapps/ moe-curriculum-BBLEARN/CurriculumOutcomeContent?id=49\&oc=76303 [accessed 2020-02-14]

43. Ontario FSG. Ontario Food and Nutrition Strategy - A Comprehensive Evidence-Informed Plan for Healthy Food and Food Systems in Ontario. Toronto, Ontario 2017 [FREE Full text]

44. Vaitkeviciute R, Ball LE, Harris N. The relationship between food literacy and dietary intake in adolescents: a systematic review. Public Health Nutr 2015 Mar;18(4):649-658 [FREE Full text] [doi: 10.1017/S1368980014000962] [Medline: 24844778]

45. Health Canada. Canada's Dietary Guidelines for Health Professionals and Policy Makers. Ottawa, Canada: Health Canada; 2019.

46. Ley P, Florio T. The use of readability formulas in health care. Psychol Health Med 1996;1(1):7-28. [doi: 10.1080/13548509608400003]

47. Schmidt-Kraepelin M, Thiebes S, Tran M, Sunyaev A. What's in the Game? Developing a Taxonomy of Gamification Concepts for Health Apps. In: Proceedings of the 51st Hawaii International Conference on System Sciences |. 2018 Presented at: HICSS'18; January 3-6, 2018; Waikoloa Village, Hawaii. [doi: 10.24251/hicss.2018.150]

48. Tamim SR, Grant MM. Exploring how health professionals create eHealth and mHealth education interventions. Educ Technol Res Dev 2016;64(6):1053-1081. [doi: 10.1007/s11423-016-9447-4]

49. Mummah SA, King AC, Gardner CD, Sutton S. Iterative development of Vegethon: a theory-based mobile app intervention to increase vegetable consumption. Int J Behav Nutr Phys Act 2016 Aug 8;13:90 [FREE Full text] [doi: 10.1186/s12966-016-0400-z] [Medline: 27501724]

50. Simons D, de Bourdeaudhuij I, Clarys P, de Cocker K, Vandelanotte C, Deforche B. A smartphone app to promote an active lifestyle in lower-educated working young adults: development, usability, acceptability, and feasibility study. JMIR Mhealth Uhealth 2018 Feb 20;6(2):e44 [FREE Full text] [doi: 10.2196/mhealth.8287] [Medline: 29463491]

51. Gabrielli S, Dianti M, Maimone R, Betta M, Filippi L, Ghezzi M, et al. Design of a mobile app for nutrition education (TreC-LifeStyle) and formative evaluation with families of overweight children. JMIR Mhealth Uhealth 2017 Apr 13;5(4):e48 [FREE Full text] [doi: 10.2196/mhealth.7080] [Medline: 28408361]

52. Tonkin E, Jeffs L, Wycherley TP, Maher C, Smith R, Hart J, et al. A smartphone app to reduce sugar-sweetened beverage consumption among young adults in Australian remote indigenous communities: design, formative evaluation and user-testing. JMIR Mhealth Uhealth 2017 Dec 12;5(12):e192 [FREE Full text] [doi: 10.2196/mhealth.8651] [Medline: 29233803]

53. Duff O, Walsh D, Malone S, McDermott L, Furlong B, O'Connor N, et al. MedFit app, a behavior-changing, theoretically informed mobile app for patient self-management of cardiovascular disease: user-centered development. JMIR Form Res 2018 Apr 27;2(1):e8 [FREE Full text] [doi: 10.2196/formative.9550] [Medline: $\underline{\text { 30684426] }}$ 
54. Story M, Kaphingst KM, Robinson-O'Brien R, Glanz K. Creating healthy food and eating environments: policy and environmental approaches. Annu Rev Public Health 2008;29:253-272. [doi: 10.1146/annurev.publhealth.29.020907.090926] [Medline: 18031223 ]

\author{
Abbreviations \\ BCT: behavior change technique \\ CFG: Canada's Food Guide \\ mHealth: mobile health \\ ORBIT: Obesity-Related Behavioral Intervention Trials
}

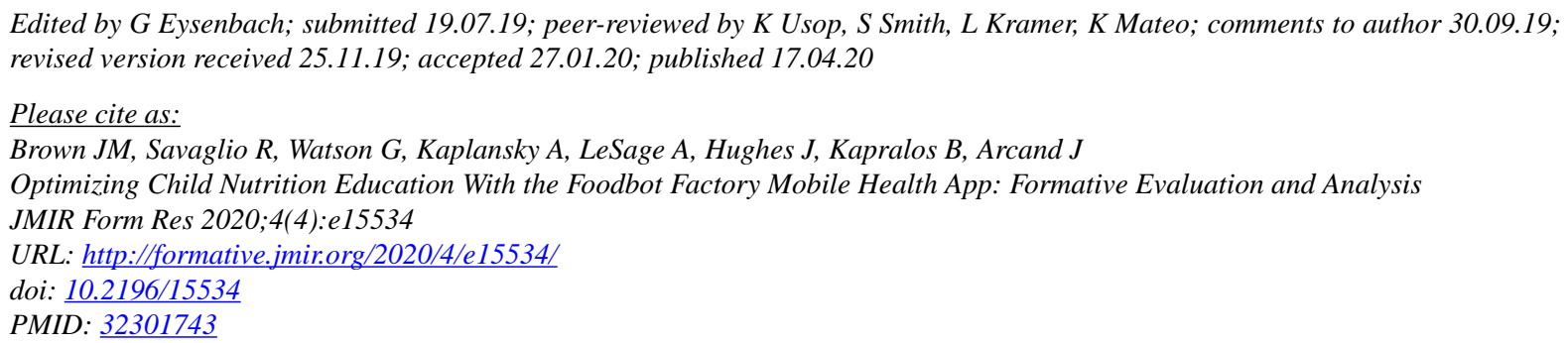

(CJacqueline Marie Marie Brown, Robert Savaglio, Graham Watson, Allison Kaplansky, Ann LeSage, Janette Hughes, Bill Kapralos, JoAnne Arcand. Originally published in JMIR Formative Research (http://formative.jmir.org), 17.04.2020. This is an open-access article distributed under the terms of the Creative Commons Attribution License (https://creativecommons.org/licenses/by/4.0/), which permits unrestricted use, distribution, and reproduction in any medium, provided the original work, first published in JMIR Formative Research, is properly cited. The complete bibliographic information, a link to the original publication on http://formative.jmir.org, as well as this copyright and license information must be included. 